\title{
Recovery priorities of people with psychosis in acute mental health in-patient settings: a Q-methodology study
}

\author{
Catherine Douglas ${ }^{1,2,}$, Lisa Wood $^{1,3}$ and Danny Taggart $^{1}$ \\ ${ }^{1}$ School of Health and Social Care, University of Essex, Wivenhoe Park, Colchester CO4 3SQ, UK, ${ }^{2}$ Merton Primary Care \\ Recovery Service, The Wilson Hospital, Cranmer Road, Mitcham, London, CR4 4TP, UK and ${ }^{3}$ North East London NHS \\ Foundation Trust, Acute and Rehabilitation Directorate, Goodmayes Hospital, Barley Lane, Ilford IG3 8XJ, UK \\ *Corresponding author. Email: Cat.Douglas@swlstg.nhs.uk
}

(Received 2 July 2019; revised 20 October 2020; accepted 21 October 2020; first published online 08 February 2021)

\begin{abstract}
Background: Personal recovery from psychosis has been explored extensively in community samples but there has been little exploration with people currently receiving care from an acute mental health in-patient setting.

Aims: The aim of this study was to explore the personal recovery priorities of people experiencing psychosis who are currently receiving care from an acute mental health in-patient ward.

Method: A Q-methodology mixed-methods approach was adopted. Thirty-eight participants were recruited from an outer London acute mental health hospital. They were required to sort 54 statements regarding personal recovery from most important to least important to reflect their recovery priorities. Thirty-six were included in the final analysis.

Results: Analysis revealed four distinct viewpoints relating to factors that promote recovery in the acute mental health in-patient setting. These were: stability, independence and 'keeping a roof over your head'; hope, optimism and enhancing well-being; personal change, self-management and social support; and symptom reduction through mental health support.

Conclusions: Acute mental health in-patient wards need to ensure that they are considering the personal recovery needs of in-patients. Symptom reduction was valued by some, but broad psychosocial factors were also of priority.
\end{abstract}

Keywords: acute mental health; hospital; mental health in-patient; psychosis; Q-methodology; recovery

\section{Introduction}

Psychosis is a mental health difficulty consisting of experiences such as hearing voices, seeing things that others do not see, holding strong beliefs that are not shared by others, and difficulties with thinking and concentration (Cooke, 2017). Psychosis was traditionally seen as a degenerative medical illness; however, due to influential service user movements and longterm outcome research, it is now understood to be a recoverable mental health experience (Law and Morrison, 2014). In defining recovery, distinctions are often drawn between clinical recovery and personal recovery (Slade et al., 2008). Clinical recovery, which operates within a medical framework, sees recovery as a dichotomous state where one is either classified as 'ill' or 'recovered', interspersed with periods of 'remission' and 'relapse' (Schrank and Slade, 2007). Personal recovery, described by Anthony (1993), emerged from the survivor movement which 
saw the emergence of service user's individual accounts of recovery. Personal recovery is synonymous with narratives of 'living well with...' suggesting that one can live a socially, functionally and emotionally fulfilling life even in the presence of continued experiences of psychosis. In relation to psychosis, personal recovery can be linked to social recovery which emphasises improvements in functioning over symptom reduction (Hodgekins et al., 2015).

The personal recovery model is often prioritised by service users (Pilgrim and McCranie, 2013) and depicts recovery as a journey with a more optimistic and less stigmatising view of mental health. It centres on utilizing personal strengths and is built on the premise that although individuals may not have full control over their experiences of psychosis, they can take control in other areas of their life (Bonney and Stickley, 2008; Jacob, 2015). Studies exploring the subjective experience of recovery from psychosis have emphasised social support, engagement in meaningful activities, and regaining independence along with personal factors such as acceptance and developing an understanding of experiences (Connell et al., 2015; Lam et al., 2011; Windell and Norman, 2013). A Q-methodology study, conducted by Wood et al. (2013), identified four key perspectives: collaborative support and understanding; emotional change through social and medical support; regaining functioning and occupational goals; and self-focused recovery. Research exploring recovery from psychosis describes it as a gradual and staged process. Pitt et al. (2007) described three stages of recovery from psychosis which include: rebuilding the self, rebuilding life, and hope for a better future. Much of the recovery literature has focused on individuals in the community who are arguably more stable in relation to their recovery journey, with a lack of research with those who are experiencing acute distress.

Mental health in-patient services have improved dramatically over recent years and are increasingly offering care underpinned by a biopsychosocial framework (Bowers, 2014). Importantly, best-practice guidelines outline that in-patient care should incorporate multidisciplinary working, psychological formulation and intervention, and involvement of those with lived experience in the delivery of their services, demonstrating its shift away from a biomedical framework (Perry et al., 2017). There have been a number of initiatives which have aimed to improve the quality of in-patient care delivered in in-patient settings, for example STAR Wards (Star Wards, 2017) and SAFE wards (Bowers, 2014), which again have improved the quality of care provided. However, the integration of recovery-focused practices is still limited. Very little research exists on the specific recovery priorities for those who are experiencing acute distress. It is likely that the recovery priorities and needs of acute mental health in-patients experiencing current severe distress, are different from those who are not hospitalised. Only one study has explored the subjective recovery experiences of service users' currently in hospital settings. Laithwaite and Gumley (2007) explored the subjective experiences of recovery of service users in a high-secure forensic setting and identified the crucial role of relationships with staff and family. Personal recovery is likely to be a contentious issue in current acute mental health in-patient settings, which are dominated by more medical approaches to treatment aiming to reduce symptoms and risk (Wood et al., 2019). Moreover, persistent service user dissatisfaction of acute psychiatric in-patient care (Care Quality Commission, 2017) may indicate that service users' recovery needs are not being considered appropriately in this setting. A recent review of service user perspectives of acute mental health in-patient care demonstrated that many psychiatric in-patients feel unsupported and dismissed, isolated from others, unsafe, and that they are receiving inadequate treatment (Wood and Alsawy, 2017), which would undoubtedly have an impact on service users' recovery experiences. It would be important to examine in-patients' perspectives on recovery to understand how their needs differ. This study aims to examine in-patients' views about factors that promote recovery from psychosis in an acute mental health in-patient setting. 


\section{Method}

\section{Design}

This study adopted a mixed-methods Q-methodology design to examine the subjective experiences of recovery from psychosis from the perspective of acute mental health in-patients (Watts and Stenner, 2012).

\section{Development of the Q-set}

The Q-set is a systematically generated set of items on a given topic domain (Watts and Stenner, 2012). The Q-set forms the foundation of the method and comprises the key statements which participants are required to sort. This occurs in a number of key stages, which are outlined below. A structured approach to Q-set formation was developed, which involves a systematic and rigid method to item development, comparable to the process of scale development (Watts and Stenner, 2012).

\section{Examination of the Q-concourse}

Initially, the concourse, defined as the communicability about a certain topic (ideas, thoughts, opinions, views), is explored. A wide-ranging number of sources relating to recovery were systematically explored including academic literature, recovery outcome measures, mental health websites, personal accounts of recovery, NHS websites, NICE guidelines, policy and white paper documents. Recent literature reviews and a Delphi study exploring recovery from psychosis were included to provide an initial framework of themes (Law and Morrison, 2014; Leamy et al., 2011; Wood and Alsawy, 2017; Wood et al., 2013). A wide range of literature was selected in order to capture the broad spectrum of recovery perspectives from medical conceptualisation to personal service user-defined approaches.

\section{Theme identification}

Following exploration of the concourse, themes were identified and extracted which represented subjective acute mental health in-patient recovery experiences. All the Q-concourse sources were read thoroughly, and systematically screened for data items which pertained to recovery from psychosis within an acute mental health in-patient context. Data items were extracted in the form of quotes, statements or questionnaire items, ensuring equal and complete coverage across all themes. During this process, ideas and opinions in relation to recovery were collected in the form of statements. Themes and subthemes were developed alongside this process by grouping together data which shared some similarity or corresponded to a particular aspect of recovery. This process of exploration and identification continued until saturation occurred and no new themes emerged. An initial 29 themes relevant to recovery from psychosis in an in-patient population were identified. Themes were reviewed and scrutinised, and multiple themes, which shared some commonality, were combined to produce over-arching themes. This produced 11 themes and 27 subthemes. Themes and subthemes are outlined in Table 1.

\section{Data extraction}

Once the themes were developed, a process of data extraction took place to generate statements for the Q-set. During this process, material such as direct quotes, ideas, research findings and items from outcome measures were collected, which totalled approximately 350 data items. These were then grouped together in relation to the themes and subthemes identified. Duplicates and overlapping items were removed, leaving 272 items grouped under the main themes and subthemes. 
Table 1. Themes and subthemes

\begin{tabular}{|c|c|c|c|c|c|c|}
\hline Relationships & Societal & \multicolumn{2}{|c|}{ Basic needs } & Psychological & Spirituality & Functional \\
\hline Professional & Community & \multirow{2}{*}{\multicolumn{2}{|c|}{$\begin{array}{l}\text { Financial } \\
\text { Accommodati- } \\
\text { on }\end{array}$}} & Identity & \multirow[t]{4}{*}{ Religion } & Activities \\
\hline Family & Stigma & & & $\begin{array}{l}\text { Hope and } \\
\text { optimism }\end{array}$ & & Employment/skills \\
\hline \multirow[t]{2}{*}{ General } & Political & \multicolumn{2}{|l|}{$\begin{array}{r}\text { Physical } \\
\text { health }\end{array}$} & Understanding & & \\
\hline & & & & Strengths and goa & & \\
\hline Treatment & \multicolumn{2}{|c|}{ Symptoms } & & Autonomy & Empowerment & Substance use \\
\hline Support & \multirow{4}{*}{\multicolumn{2}{|c|}{$\begin{array}{l}\text { Psychosis symptoms } \\
\text { General mental health }\end{array}$}} & \multirow{4}{*}{\multicolumn{2}{|c|}{$\begin{array}{l}\text { Self-reliance/management } \\
\text { Time alone }\end{array}$}} & Control & \multirow[t]{4}{*}{ Drugs/alcohol } \\
\hline Hospital setting & & & & & Choice & \\
\hline $\begin{array}{l}\text { Life as an } \\
\text { in-patient }\end{array}$ & & & & & & \\
\hline Medication & & & & & & \\
\hline
\end{tabular}

\section{Q sampling}

The next step involved generating a list of statements to form the Q-set. The target number of statements was between 40 and 80, which is suggested as a suitable size for a Q-set, whilst maintaining a representative coverage of the topic (Stainton Rogers, 1995; Watts and Stenner, 2012). The items and themes were read and reviewed. A process of quota sampling was employed whereby two items were chosen to represent each subtheme. This process involved refining and reducing the items in each subtheme to fully capture the views, and opinions expressed. This process resulted in 54 items considered to capture the essence of the data in each subtheme. Each subtheme consisted of two items; however, two subthemes ('Relationships - General' and 'Functional - Activities') had three items each as these additional items captured something distinct in the data that was not present elsewhere. The next step was to transform the final 54 items into a usable Q-set, by a process of refining and rewording (Table 2).

\section{Participants}

This study recruited 38 participants from four adult acute mental health in-patient wards in an outer London hospital. The inclusion criteria were: participants with a schizophrenia-spectrum diagnosis or those who met entry criteria for an Early Intervention for Psychosis service; currently receiving care from an acute mental health in-patient unit; and aged between 18 and 65 years. The exclusion criteria were non-English speakers (due to translation costs); those deemed too unwell to participate (by the psychology team); anyone lacking capacity to consent; and those already involved in a research study relating to recovery.

\section{Procedure}

Potential participants were screened by the clinical teams for suitability with reference to the inclusion and exclusion criteria. Interested participants were referred to the researcher. Details of the study were explained to the participants and written informed consent was gained. Participants first completed the pre-sort task where they were handed the Q-set and asked to sort the Q-set cards into three piles: important, unimportant or neutral, in response to the condition of instruction ('Which factors are most important to your recovery?').

Participants were then presented with the distribution grid (Fig. 1) and instructed to start by arranging the 'important' pile of cards onto the grid by first selecting the three most important statement cards and placing them in the +5 column. They were then asked to select the four next most important cards and place them in the +4 column, and so on. The same process was then 
Table 2. Table of Q-set items

\begin{tabular}{|c|c|}
\hline Items & \\
\hline 1 Government support & 28 Ability to cope with my mental health \\
\hline 2 Frequency of mental health experiences & 29 Support with financial problems \\
\hline 3 Helpfulness of medication & 30 Society's understanding of my mental health \\
\hline 4 Life having a purpose & 31 Support from family/loved ones \\
\hline 5 Being part of a community/society & 32 Staff treating me with dignity and respect \\
\hline 6 Involvement of family/loved ones & 33 Understanding from staff \\
\hline 7 Impact on memory and concentration & 34 Religion/spirituality to cope \\
\hline 8 Feelings of loneliness & 35 Managing feelings of boredom \\
\hline 9 Control over circumstances & 36 Support from mental health services \\
\hline 10 Hospital activities & 37 Impacts of mental health on my ability to work \\
\hline 11 Socialising with others & 38 My religious/spiritual beliefs being respected \\
\hline 12 Suitability of housing (outside of hospital) & 39 Access to employment/education/skills courses \\
\hline 13 Impacts on mood/emotions & 40 Others respecting my right to be alone \\
\hline 14 Self-confidence & 41 The distress my mental health symptoms/voices cause me \\
\hline 15 Being more than my diagnosis/illness & 42 Stable living arrangements \\
\hline 16 Helpfulness of therapy & 43 Access to equal opportunities \\
\hline 17 Enjoyment of hobbies/activities & 44 Looking after one's self \\
\hline 18 Impacts on physical health & 45 Not being a burden to others \\
\hline 19 Financial stability & 46 Having privacy \\
\hline 20 Being positively viewed by others. & 47 Support from hospital staff \\
\hline 21 Safeness in hospital & 48 Being involved in my care \\
\hline 22 Meaningful community activities & 49 Reducing drug/alcohol use \\
\hline 23 Medication side-effects & 50 Support to set own life goals \\
\hline 24 Comfortableness of the hospital ward/environment & 51 Understanding my mental health experiences \\
\hline 25 Exercise and eating well & 52 Having my diagnosis explained \\
\hline 26 Positive perceptions of relationships & 53 Believing I can get better \\
\hline 27 Impacts on personal freedoms and rights & 54 Self-worth \\
\hline
\end{tabular}

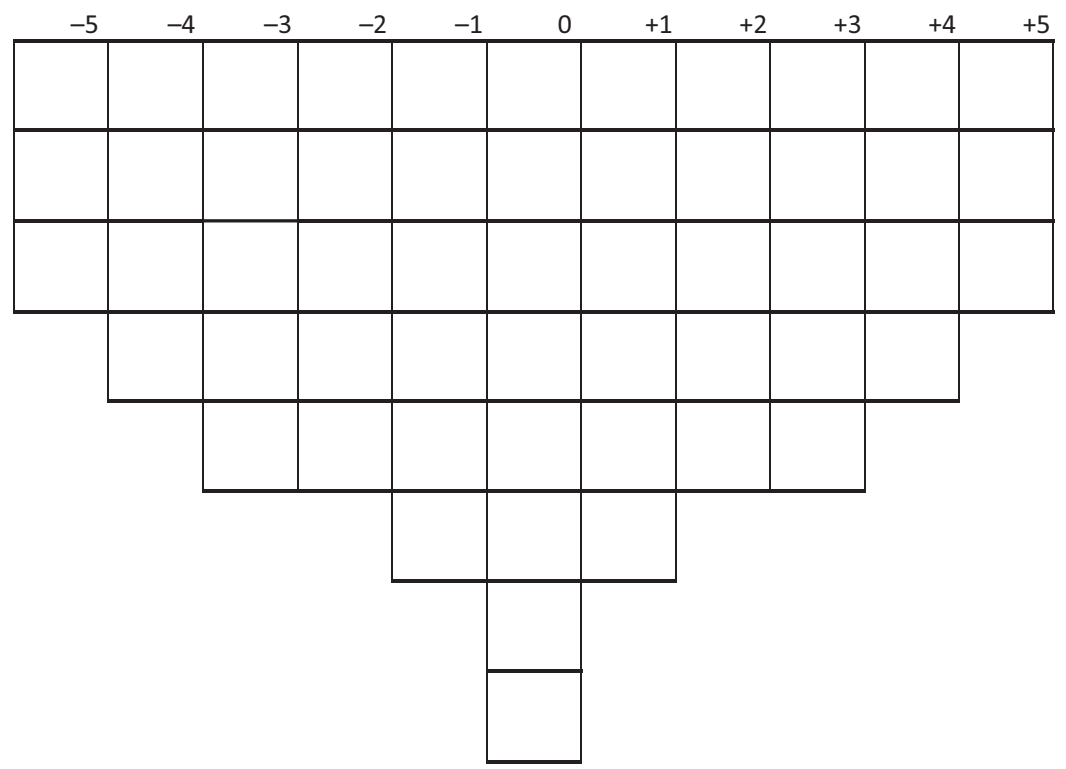

Figure 1. Distribution grid. 
completed for the 'unimportant' and 'neutral' piles. Once the sorting was completed, participants were given the opportunity to make any changes. Participants were then given a feedback form and asked four brief questions about the task, which included asking them to identify their reasons for selecting the top three and bottom three statements, identifying anything which was missing, and any other relevant feedback. Notes with regard to engagement and explanations given by participants about their sorts were made by the researcher during the task.

\section{Data analysis}

Analysis was conducted using Q-method software PQ method (version 2.11; Schmolck, 2002). A principal components analysis with varimax rotation was used to identify the most parsimonious solution explaining the most variance. Factors produced were based on groups of participants who shared similar viewpoints about recovery within an in-patient setting. Factor extraction drew upon statistical and theoretical considerations. All eigenvalues for factors had to be above 1 (Kaiser-Guttman criteria; Guttman, 1954; Kaiser, 1960), the crossproduct criteria of a factor had to be twice the size of the standard error (Brown, 1980), factors had to have at least two loading Q-sorts which had a factor loading of 0.36 or above (Watts and Stenner, 2012). Qualitative feedback was gathered through a feedback questionnaire (see Supplementary material) to examine participants' reasons for their Q-sort distribution. Finally, the final factor names were developed drawing upon the most highly endorsed statements, qualitative feedback, and consideration of relevant recovery literature.

\section{Results}

\section{Participant demographics}

A total of 38 participants were recruited, but only 36 were included in the analysis. Two participants were excluded due to not completing the task, making their results invalid (Krueger et al., 2001). Participant demographics for the final 36 participants are given in Table 3. The majority of participants were male (89\%), White British (44\%), diagnosed with schizophrenia (44\%), and were currently experiencing psychosis $(78 \%)$. The average age of the sample was 40 years (SD 13.08), and the average number of admissions was 4.83 (SD 5.47).

\section{Q-method analysis}

The analysis resulted in a four-factor solution explaining $38 \%$ of the study variance. Twenty-five of 36 participants' Q-sorts loaded significantly on one of the four factors. Participant demographics per factor are outlined in Table 3. The factor loadings, eigenvalues and explained variances are given in Table 4.

\section{Factor 1: Stability, independence and 'keeping a roof over your head'}

Factor 1 explains $9 \%$ of the study variance, with six participants loading onto the factor, and had an eigenvalue of 4.84. This group had the lowest number of hospital admissions and were focused on improving the practical aspects of their life in the community.

The factor consisted of people who prioritised stable living arrangements, for example having ' $a$ roof over your head before you can do anything' (P13) and described how financial and employment security were crucial to maintain this. This caused participants significant worry, 'I worry about whether I can keep looking after myself and I need a secure residence to have, because if I don't know where I will be from day to day there is no point in trying' (P26). Feeling in control of their personal and living circumstances, alongside government support, were particularly valued by this group [items $1,9,19,12,42,28,29,39,44$; e.g. government support, +5 ; control over 
Table 3. Demographic information for study participants

\begin{tabular}{|c|c|c|c|c|c|}
\hline & $\begin{array}{l}\text { Total sample } \\
\quad(n=36)\end{array}$ & $\begin{array}{l}\text { Factor } 1 \\
(n=6)\end{array}$ & $\begin{array}{c}\text { Factor } 2 \\
(n=8)\end{array}$ & $\begin{array}{c}\text { Factor } 3 \\
(n=7)\end{array}$ & $\begin{array}{l}\text { Factor } 4 \\
(n=4)\end{array}$ \\
\hline \multirow[t]{2}{*}{ Age - mean $(S D)$, range } & 39.97 (13.08) & $37(12.94)$ & $41.5(15.3)$ & $41.29(15.5)$ & 39.5 (12.79) \\
\hline & $22-65$ & $24-53$ & $22-65$ & $24-63$ & $26-54$ \\
\hline Admissions - mean (SD) & $4.86(5.47)$ & $2.83(3.13)$ & $6.25(6.39)$ & $3.14(2.54)$ & $7.5(10.5)$ \\
\hline $\begin{array}{l}\text { Duration of psychotic disorder in } \\
\text { years - mean }(S D)\end{array}$ & $10.67(10.08)$ & $6.24(4.85)$ & $10.38(7.85)$ & $4.03(5.15)$ & $4.5(4.92)$ \\
\hline \multicolumn{6}{|l|}{ Gender } \\
\hline Male (\%) & $32(89)$ & $6(100)$ & $8(100)$ & $5(72)$ & $2(50)$ \\
\hline Female (\%) & $4(11)$ & 0 & 0 & $2(28)$ & $2(50)$ \\
\hline \multicolumn{6}{|l|}{ Ethnicity } \\
\hline Asian & $3(8.3)$ & $1(16.7)$ & $1(12.5)$ & 0 & 0 \\
\hline Black & $13(36.1)$ & $2(33.3)$ & $3(37.5)$ & $2(28.6)$ & $1(25)$ \\
\hline White & $16(44.4)$ & $2(33.3)$ & $2(25)$ & $5(71.4)$ & $3(75)$ \\
\hline Mixed & $3(8.3)$ & 0 & $2(25)$ & 0 & 0 \\
\hline Other & $1(2.8)$ & $1(16.7)$ & 0 & 0 & 0 \\
\hline \multicolumn{6}{|l|}{ Diagnosis } \\
\hline Schizophrenia & $16(44.4)$ & $2(33.3)$ & $5(62.5)$ & $3(42.9)$ & $1(25)$ \\
\hline Experiences of psychosis & $8(22.2)$ & $2(33.3)$ & $1(12.5)$ & $1(14.3)$ & $1(25)$ \\
\hline Other/none & $12(33.3)$ & $2(33.3)$ & $2(25)$ & $3(42.9)$ & $2(50)$ \\
\hline \multicolumn{6}{|l|}{ Current experiences of psychosis } \\
\hline Yes & $28(77.8)$ & $5(83.3)$ & $4(50)$ & $7(100)$ & $3(75)$ \\
\hline No & $8(22.2)$ & $1(16.7)$ & $4(50)$ & 0 & $1(25)$ \\
\hline
\end{tabular}

Table 4. Q-sort matrix

\begin{tabular}{|c|c|c|c|c|}
\hline Participant & Factor 1 & Factor 2 & Factor 3 & Factor 4 \\
\hline 1 & 0.0514 & 0.4731 & 0.4763 & 0.0809 \\
\hline 2 & -0.0141 & 0.5452 & -0.1239 & 0.0958 \\
\hline 3 & 0.5885 & -0.0251 & 0.0144 & -0.0560 \\
\hline 5 & 0.3649 & 0.0139 & -0.0710 & 0.1039 \\
\hline 6 & 0.1794 & -0.2328 & 0.0337 & 0.6655 \\
\hline 7 & 0.0323 & 0.6042 & 0.2107 & -0.0671 \\
\hline 8 & 0.0388 & 0.3115 & 0.4740 & 0.2827 \\
\hline 9 & -0.1727 & 0.6314 & -0.0279 & 0.1104 \\
\hline 11 & 0.7916 & -0.0698 & 0.2401 & 0.3115 \\
\hline 14 & 0.1639 & -0.0819 & 0.6413 & -0.0890 \\
\hline 15 & 0.4533 & 0.1252 & -0.0714 & 0.2308 \\
\hline 17 & 0.0726 & 0.5777 & -0.1385 & -0.1925 \\
\hline 18 & -0.2638 & 0.3806 & -0.0180 & -0.0072 \\
\hline 19 & 0.2067 & 0.5309 & 0.0272 & -0.1902 \\
\hline 21 & 0.6417 & 0.0026 & 0.1608 & 0.2558 \\
\hline 22 & -0.1521 & -0.0580 & 0.4169 & -0.0519 \\
\hline 24 & 0.6195 & 0.0016 & 0.2326 & -0.1007 \\
\hline 25 & 0.3146 & -0.2137 & -0.0034 & 0.5215 \\
\hline 28 & -0.0158 & 0.6827 & 0.1509 & -0.0545 \\
\hline 30 & -0.2954 & 0.1271 & 0.5418 & 0.1601 \\
\hline 31 & -0.2039 & 0.2558 & -0.3706 & -0.2081 \\
\hline 32 & 0.2473 & -0.0784 & -0.0696 & 0.7007 \\
\hline 33 & 0.0345 & 0.6073 & 0.3509 & -0.0153 \\
\hline 34 & 0.2494 & 0.1072 & 0.4164 & 0.2756 \\
\hline 35 & -0.0693 & 0.1100 & 0.0893 & 0.5132 \\
\hline 36 & 0.0617 & 0.2035 & 0.6241 & -0.1385 \\
\hline Explained variance (\%) & 9 & 11 & 10 & 8 \\
\hline Eigenvalue & 4.84 & 4.13 & 2.36 & 2.32 \\
\hline
\end{tabular}


circumstances (money, living, employment etc.), +5 ; financial stability, +5 ]. Reducing substance use was rated more importantly by this group when compared with the other three groups (item 49: reducing drug/alcohol use, +2 ).

This group did value improving their mental health symptoms but it was improvement in the day-to-day impact of their symptoms, which was prioritised (items 41, 7, 28, 13, 37; e.g. the distress my mental health symptoms/voices cause me, +4 ; impact on memory and concentration, +3 ; ability to cope with my mental health, +3 ). This group valued having input from mental health services to help them cope with their experiences of psychosis. Medication was rated more importantly by this group when compared with other groups. Additionally, this group consisted of those who valued feeling in control of their circumstances and as such being involved in decisions relating to their treatment and care was considered important. Psychological therapies (items 3, 48, 36, 16; e.g. support from mental health services, +1 ; helpfulness of therapy, -1 ), relationships and religion (items $6,8,11,26,31,45,20,5,34,38$; e.g. religion/spirituality to cope, -5 ; positive perceptions of relationships, -4 ) were seen to be less important.

\section{Factor 2: Hope, optimism and enhancing well-being}

This factor explained $11 \%$ of the study variance and had an eigenvalue of 4.13 . Eight participants loaded significantly on this factor (Table 2). This factor consisted of people who reported that enhancing the positive aspects of mental well-being were the most important factors to recovery, and were the only group to view reduction of mental health symptoms as the least important factors. This group had a high number of admissions and longest duration of psychosis, which may reflect enduring experiences of psychosis in the sample. Participants in this group appeared to adopt a living with symptoms approach to recovery and rejected the medical model (item 3: helpfulness of medication, -4).

This group prioritised the interpersonal and intrapersonal factors of recovery and explained how distressing experiences of psychosis and hospitalisation can hinder these. 'Upon entry to hospital your confidence has taken a bashing and it's important that your self-worth and purpose is reinstated' (P4). Maintaining hope and optimism were of particular importance (items 53, 4, 14, 54; e.g. believing I can get better, +5 ; life having a purpose, +5 ; self-confidence, +4$)$. Participants engaged in a variety of non-clinical coping strategies to cope, including turning to religion and spirituality (item 34: religion/ spirituality to cope, +5 ), hobbies and exercise (items 25,17 : exercise and eating well, +3 , meaningful community activities, +1 ). This group valued their relationships with peers, staff and family (items 26 , $32,31,5$; e.g. positive perceptions of relationships, +4 ; staff treating me with dignity and respect, +3 ).

Finally, this group identified positive aspects to their experiences, which may indicate that some of their symptoms of psychosis were experienced as pleasant. For example, one participant spoke of his voices as being 'nice most of the time'. All symptoms aspects of their experiences were rated as low (items $2,3,7,41,18,52$; e.g. frequency of mental health experiences, -5 ; impact on memory and concentration, -5 ; the distress my mental health/symptoms/voices cause me, -5 ).

\section{Factor 3: Personal change, self-management and social support}

This factor explained $10 \%$ of the study variance, had an eigenvalue of 2.36 , and seven participants loaded onto this factor. One participant's Q-sort loaded negatively on this factor, meaning that this participant's view was negatively associated with this factor. This group had the shortest duration of psychosis and the second lowest average number of admissions, probably representing people with early stage psychosis.

This factor consisted of people who valued self-management and coping with their experiences without the input of mental health services. Participants wanted to reduce the impact of mental and physical health symptoms and enhance their sense of purpose and self-belief as important factors in their recovery (items $7,37,14,41,27,18,13,23,4,53,54$; e.g. impact on memory 
and concentration, +5 ; impacts of mental health on my ability to work, +4 ; self-confidence, +4 ; impacts on my personal freedoms and rights, +4$)$.

This group valued self-management and utilising their own resources to facilitate recovery (items 28, 34, 44, 25; e.g. how able I am to cope with my mental health experiences myself, +5 ; how often I exercise and eat well, +5$)$. One participant wrote 'exercise helps release endorphins and provides a sense of achievement' (P16) and another spoke of how their religion helps them to cope, 'I believe that God and me personally can overcome anything' (P32). Individuals in this group valued feeling in control of their circumstances and being able to function independently of formal forms of support [items 44, 9; looking after one's self (e.g. daily tasks), +4 ; control over circumstances (money, living, employment etc.), +3]. In contrast, access to, and support from mental health services, particularly in-patient services, were seen as some of the most unimportant factors in recovery (items 3, 32, 47, 36, 16, 10, $33,52,24$; e.g. comfortableness of the hospital ward/environment, -5 ; support from hospital staff, -4 ; having my diagnosis explained, -4 ; helpfulness of therapy, -3 ).

This group valued having support from loved ones and their broader social system (items 31, $11,26,46,40$; e.g. support from family/loved ones, +3 ; socialising with others, +2 ). One participant stated, 'as a society we enjoy seeing each other through the good as well as the bad times' (P16). Individuals recognised relational factors as affecting their recovery and felt that feelings of loneliness and being a burden would hinder their recovery (items 45, 8; e.g. not being a burden to others, +1 ).

\section{Negatively loading Q-sort: psychosis as a gift from God}

One participant loaded negatively onto this factor, meaning the participant's view was opposed to the rest of the group. This participant was male, aged 63, but also experiencing his own first episode of psychosis. This participant described his experiences as 'a gift from God' (P33) and described the presence of voices as a positive experience. Contrasting with the group, this participant did not value coping through self-management (items $7,28,27,37,13$ ). This participant valued having a positive in-patient experience (items 20, 24, 10, 33, 36, 47, 32) and valued integrating back into the community (items 5, 22, 39, 17, 19, 42).

\section{Factor 4: Symptom reduction through mental health support}

This factor explained $8 \%$ of the study variance, had four people loading onto it and had an eigenvalue of 2.32. This group had the highest number of admissions. This group appeared to represent those with the most acute symptoms and related distress.

This group valued reducing the distress caused by mental health experiences and finding ways of coping (items $28,41,7,13,2,18,23$; e.g. how much distress my mental health symptoms/voices cause me, +5 ; ability to cope with my mental health, +5 ). Participants viewed their symptoms as burdensome and affecting different areas of their life such as work (items 27, 37; e.g. impacts of mental health on my ability to work, +3$)$. This group also valued social acceptance and acknowledged the social impact of mental health (items 52, 30: having my diagnosis explained, +4 ; society's understanding of my mental health, +3 ).

For this group, having clinical treatment was viewed as integral to recovery and individuals were open to a variety of types of support, such as therapy, medication or psychoeducation (items $36,3,16$, 52 ; support from mental health services, +5 ; having my diagnosis explained, +4 ; helpfulness of therapy, +4 ; helpfulness of medication, +1 ). The group were also sensitive to the quality and input into the care they received (items 33, 47, 21, 24, 32; e.g. support from hospital staff, +3 ; safeness in hospital, +3 ; being treated by staff with dignity and respect, +2 ). Additionally, they valued the amount of involvement that both they and their family had in their treatment and care (items 48, 6; e.g. being involved in my care, +4 ; involvement of family/loved ones, +3 ). 
The least important factors for this group were spiritual (items 34, 38, 49; e.g. religion/spirituality to cope, -5 ; my religious/spiritual beliefs being respected, -5 ), relational (items 26, 5, 11, 20, 31; e.g. positive perceptions of relationships, -3 ; being part of a community/society, -2 ), and personal coping strategies (items 17, 50, 10, 22, 25; e.g. enjoyment of hobbies/activities, -4; support to set own life goals, -4 ; hospital activities, -3 ).

\section{Feedback on the task}

The 36 participants who contributed to the analysis gave feedback on the task. Overall, the majority of participants reported finding the completion of the Q-sort a positive experience and appreciated the opportunity to discuss their recovery, 'I enjoyed the research interview as I was helped to understand myself better and give my views which is important to me' (P 4). The only negative feedback was that some participants found it difficult concentrating for the full duration of the task and found the task a challenge, 'I can't think and describe all my psychological system in a few minutes' (P17). Participants were offered regular breaks to try and support them to undertake the task.

\section{Discussion}

This study aimed to explore the recovery priorities of an in-patient population of service users who experience psychosis using a Q-methodology design. Analysis revealed four distinct viewpoints that were present relating to recovery priorities. These were: Stability, independence and 'keeping a roof over your head'; Hope, optimism and enhancing well-being; Personal change, self-management and social support; and Symptom reduction through mental health support. These results suggest that in-patients hold different views about what is important to them in recovery.

The factor of Stability, independence and 'keeping a roof over your head' demonstrated the importance of basic needs such as housing, money and employment and being independently able to achieve these. A similar theme was also identified in a Q-methodology study in community samples demonstrating the importance of prioritising social issues across the psychosis spectrum (Wood et al., 2013). This group's views of recovery aligns with a functional recovery model with finance, housing and employment (Whitley and Drake, 2010). Research suggests that poorer mental health is linked with increased difficulty with issues relating to welfare rights (Balmer et al., 2010; Mehta et al., 2018). Additionally, poverty is suggested as a risk factor in the development of psychosis (Dean and Murray, 2005). For individuals in this group, getting support to meet their basic needs of housing and finance first, may be far more effective in helping them achieve recovery than viewing these as separate or 'additional' needs. Slade et al. (2014) argue for 'everyday solutions for everyday problems' and suggest that having a place to live, should be the base from which people with severe mental illness can achieve numerous recovery goals and improve quality of life'.

The second factor of Hope, optimism and enhancing well-being represented people with a longer duration of psychosis and those who valued personal recovery factors such as hope, optimism and self-worth. This group were willing to access support from services; however, their preference was to manage their experiences through self-coping or relational support. This group also highlighted religion as an important coping mechanism to their recovery. Religion and spirituality have been linked with enhancing well-being and are implicated in transformative experiences of psychosis as a means of making sense of experiences (Heffernan et al., 2016). This factor may suggest that those with persistent mental health difficulties have less faith in mental health services in treating their difficulties, and therefore are turning to other alternatives. 
The third factor of Personal change, self-management and social support represented those in the early stages of psychosis. This group valued self-management strategies and finding individual ways to cope supporting previous personal recovery literature, which has identified the importance of idiosyncratic coping strategies (Laithwaite and Gumley, 2007; Lam et al., 2011; Pitt et al., 2007). Moreover, social relationships were highlighted as crucial to recovery aligning with a social model, which emphasises social support and inclusion (Mezzina et al., 2006). This group thought it was important to see themselves beyond their diagnosis and due to the value they placed on social factors, it is possible they were conscious of the social impact of accessing services or accepting a diagnosis. Research has suggested that stigma and shame around diagnosis, along with denial and lack of information, provides a barrier to accessing support in the early phases of psychosis and to recovery (Wood and Alsawy, 2017).

Factor four of Symptom reduction through mental health support represented those who experienced acute and distressing episodes of psychosis. For this group, their primary focus was to improve their experiences of psychosis through support from mental health services. In contrast with much of the research on recovery, these individuals placed much less value on social, functional and intrapersonal factors (Law and Morrison, 2014; Wood et al., 2013). This group's preference for more clinical forms of support is in line with research suggesting that those who view mental health through a medical model are less likely to endorse self-help (Pattyn et al., 2013). These individuals placed high value on social acceptance. Their medicalised conceptualisations of mental health may lead them to being more susceptible to perceptions of stigma from others or to experiences of self-stigma (Longdon and Read, 2017). This is an important consideration as stigma poses a significant barrier to recovery and is reportedly more of an issue with diagnoses such as schizophrenia (Schulze and Angermeyer, 2003). Service user research has indicated that diagnoses can be useful in supporting access to treatment and giving a name to experiences (Pitt et al., 2009). However, despite these benefits, research indicates that even when medical labels are experienced positively, the associated experiences of social exclusion remain (Pitt et al., 2009).

There are a number of strengths to the study. This is the first study to explore in-patients' recovery needs using Q-methodology. Q-methodology has a number of strengths including its ability to incorporate a larger sample of participants whilst still being able to identify qualitatively meaningful results. Moreover, it is a participant-friendly method which was supported by participant feedback (Dudley et al., 2009; Wood et al., 2013). A breadth of literature was used to develop the Q-set which maximises the validity of included statements. A limitation to the development of the Q-set was the lack of quality checks and concurrent screening of the literature, which may have led to bias in the development of the Q-set. However, the structured Q-set development method was chosen over the unstructured approach (Watts and Stenner, 2012), which hopefully would have minimised this bias. Another limitation was that we only gained very limited feedback on participants' experiences of the task as we did not explicitly ask participants this on the feedback form. The feedback form asked for 'any other feedback', where some participants chose to write feedback about undertaking the Q-sort. Although the feedback we did receive was mostly positive, it would have been preferable to explicitly ask people about their experiences of undertaking this research given its novel nature. Another limitation of the Q-methodology was not being able to identify further detail about the recovery factors outlined. We were able to identify, for example, that spirituality and religion are important to in-patients recovering from psychosis but we were not able to identify further detail as to how or why. One of the limitations was the extended length of time it took some participants to complete the study. Some participants described difficulty with concentration and being unable to fully engage in the task, which is reflected in a feedback statement from one participant. Another limitation was the relatively small sample size; often a sample of 40-60 is recommended for Q-methodology (Stainton Rogers, 1995). Also, the sample included $89 \%$ of male participants which means the findings may not be reflective of female in-patients experiencing psychosis. However, in-patient 
settings often do have an over-representation of males with psychosis due to factors such as drug use, and risk behaviours such as violence and aggression which make admission more likely. Finally, data from 11 participants did not load significantly onto one of the factors, which may mean there are additional viewpoints that may not be accounted for. However, the aim in Q-method is to uncover the main and distinct viewpoints that are present among the group, and as such a limitation of the method is that it is rarely inclusive of every participant's viewpoint. Finally, only 25 of 38 participants contributed to the final factor structure, which only explained $38 \%$ of the total variance. Although it is recommended that theoretical grounds should be prioritised over statistical ones when determining a factor structure (Watts and Stenner, 2012), the low levels of loading participants and low explained variance may indicate that the best-fitting model was not chosen and may not be comprehensive in capturing the view of in-patients experiencing psychosis.

This study has a number of important clinical implications. Firstly, this research has identified that people have varying needs when considering recovery. Some prioritised medical approaches, whereas others prioritised psychological, social and spiritual approaches. Arguably, mental health in-patient settings are dominated by the medical model (Wood et al., 2019), and therefore may not be meeting the needs of a number of in-patients. It is important that recovery is assessed within the mental health in-patient setting and a broad biopsychosocial approach to recovery is adopted. In line with current policy, this highlights the need for a range of treatment options to be available and for service users to have choice in this process (Perry et al., 2017). Social factors should also be prioritised. The SafeWards model suggests that staff on in-patient wards should have knowledge of, and provide support with, service users' external circumstances (e.g. housing and financial support), which has been highlighted as important by this research project (Bowers, 2014). However, this should be the priority for in-patient care with service users' social circumstances and basic needs being met before any further mental health treatment can occur (Wood et al., 2019). Finally, spiritual support was highlighted as important, which indicates the importance of having access to services such as chaplaincy, and for spiritual and religious needs to be integrated into service users' care plans. More specifically, it should be a component of how their mental health experiences are understood and cared for during an admission.

In summary, four distinct recovery factors were identified which demonstrate the varying approaches to recovery from the perspective of mental health in-patients. A thorough understanding and holistic approach to support these needs is required.

Supplementary material. To view supplementary material for this article, please visit https:/doi.org/10.1017/ S1352465820000892

Acknowledgements. None.

Financial support. None.

Conflicts of interest. None.

Ethics statement. The study received full Health Research Authority (IRAS ID 205433) and NHS Research Ethics Committee (17/EE/0140) approval. The authors have abided by the Ethical Principles of Psychologists and Code of Conduct as set out by the BABCP and BPS (2014).

\section{References}

Anthony, W. A. (1993). Recovery from mental illness: the guiding vision of the mental health service system in the 1990 s. Psychosocial Rehabilitation Journal, 16, 11. doi: 10.1037/h0095655

Balmer, N. J., Pleasence, P., \& Buck, A. (2010). Psychiatric morbidity and people's experience of and response to social problems involving rights. Health \& Social Care in the Community, 18, 588-597. doi: 10.1111/j.1365-2524.2010.00927.x

Bonney, S., \& Stickley, T. (2008). Recovery and mental health: a review of the British literature. Journal of Psychiatric and Mental Health Nursing, 15, 140-153. doi: 10.1111/j.1365-2850.2007.01185.x 
Bowers, L. (2014). Safewards: a new model of conflict and containment on psychiatric wards. Journal of Psychiatric and Mental Health Nursing, 21, 499-508. doi: 10.1111/jpm.12129

British Psychological Society (BPS) (2014). Code of Human Research Ethics. British Psychological Society. London.

Brown, S. R. (1980). Political Subjectivity: Applications of Q Methodology in Political Science. New Haven: Yale University Press.

Care Quality Commission (2017). Adult Inpatient Survery 2017. London, Care Quality Commission.

Connell, M., Schweitzer, R., \& King, R. (2015). Recovery from first-episode psychosis and recovering self: a qualitative study. Psychiatric Rehabilitation Journal, 38, 359-364. doi: 10.1037/prj0000077

Cooke, A. (2017). Understanding psychosis and schizophrenia: why people sometimes hear voices, believe things that others find strange, or appear out of touch with reality... and what can help. British Psychological Society.

Dean, K., \& Murray, R. M. (2005) Environmental risk factors for psychosis. Dialogues in Clinical Neuroscience, 7, 69-80.

Dudley, R., Siitarinen, J., James, I., \& Dodgson, G. (2009). What do people with psychosis think caused their psychosis? A Q methodology study. Behavioural and Cognitive Psychotherapy, 37, 11-24. doi: 10.1017/S1352465808004955

Guttman, L. (1954). Some necessary conditions for common-factor analysis. Psychometrika, 19, 149-161. doi: 10.1007/ BF02289162

Heffernan, S., Neil, S., Thomas, Y., \& Weatherhead, S. (2016). Religion in the recovery journey of individuals with experience of psychosis. Psychosis: Psychological, Social and Integrative Approaches, 8, 346-356. doi: 10.1080/17522439. 2016.1172334

Hodgekins, J., French, P., Birchwood, M., Mugford, M., Christopher, R., Marshall, M., Everard, L., Lester, H., Jones, P. B., Amos, T., Singh, S., Sharma, V., Morrison, A. P., \& Fowler, D. (2015). Comparing time use as a measure of social functioning in individuals at different stages of psychosis and in a non-clinical comparison group. Schizophrenia Research, 161, 188-193.

Jacob, K. S. (2015). Recovery model of mental illness: a complementary approach to psychiatric care. Indian Journal of Psychological Medicine, 37, 117-119. doi: 10.4103/0253-7176.155605

Kaiser, H. F. (1960). The application of electronic computers to factor analysis. Educational and Psychological Measurement, 20, 141-151. doi: 10.1177/001316446002000116

Krueger, R. A., Casey, M. A., Donner, J., Kirsch, S., \& Maack, J. N. (2001). Social Analysis: Selected Tools and Techniques. Washington, USA: Social Development Family of the World Bank.

Laithwaite, H., \& Gumley, A. (2007). Sense of self, adaptation and recovery in patients with psychosis in a forensic NHS setting. Clinical Psychology \& Psychotherapy, 14, 302-316. doi: 10.1002/cpp.538

Lam, M. M. L., Pearson, V., Ng, R. M. K., Chiu, C. P. Y., Law, C. W., \& Chen, E. Y. H. (2011). What does recovery from psychosis mean? Perceptions of young first-episode patients. International Journal of Social Psychiatry, 57, 580-587. doi: 10.1177/0020764010374418

Law, H., \& Morrison, A. P. (2014). Recovery in psychosis: a Delphi study with experts by experience. Schizophrenia Bulletin, 40, 1347-1355. doi: 10.1093/schbul/sbu047.

Leamy, M., Bird, V., Le Boutillier, C., Williams, J., \& Slade, M. (2011). Conceptual framework for personal recovery in mental health: systematic review and narrative synthesis. British Journal of Psychiatry, 199, 445-452. doi: 10.1192/bjp. bp. 110.083733

Longdon, E., \& Read, J. (2017). 'People with problems, not patients with illnesses': using psychosocial frameworks to reduce the stigma of psychosis. Israel Journal of Psychiatry and Related Sciences, 54, 24-28.

Mehta, J., Clifford, E., Taggart, D. and Speed, E. (2018). 'Where your mental health disappears overnight': disabled people's experiences of the employment and support allowance work related activity group. Report prepared for the House of Lords, University of Essex and Inclusion, London.

Mezzina, R., Davidson, L., Borg, M., Marin, I., Topor, A., \& Sells, D. (2006). The social nature of recovery: discussion and implications for practice. American Journal of Psychiatric Rehabilitation, 9, 63-80. doi: 10.1080/15487760500339436.

Pattyn, E., Verhaeghe, M., Sercu, C., \& Bracke, P. (2013). Medicalizing versus psychologizing mental illness: what are the implications for help seeking and stigma? A general population study. Social Psychiatry and Psychiatric Epidemiology, 48, 1637-1645. doi: 10.1007/s00127-013-0671-5.

Perry, J., Palmer, L., Thompson, P., Worrall, A., \& Chaplin, R. (2017). Standards for Inpatient Mental Health Services. London: Royal College of Psychiatry.

Pilgrim, D., \& McCranie, A. (2013) Recovery and Mental Health: A Critical Sociological Account. Palgrave Macmillan.

Pitt, L., Kilbride, M., Nothard, S., Welford, M., \& Morrison, A. P. (2007). Researching recovery from psychosis: a user-led project. Psychiatric Bulletin, 31, 55-60. doi: 10.1192/pb.bp.105.008532

Pitt, L., Kilbride, M., Welford, M., Nothard, S., \& Morrison, A. P. (2009). Impact of a diagnosis of psychosis: user-led qualitative study. Psychiatric Bulletin, 33, 419-423. doi: 10.1192/pb.bp.108.022863

Schmolck, P. (2002). PQ method (version 2.11). Retrieved from: http://schmolck.userweb.mwn.de/qmethod/

Schrank, B., \& Slade, M. (2007). Recovery in psychiatry. Psychiatric Bulletin, 31, 321-325.

Schulze, B., \& Angermeyer, M. C. (2003). Subjective experiences of stigma. A focus group study of schizophrenic patients, their relatives and mental health professionals. Social Science \& Medicine, 56, 299-312. doi: 10.1177/1049732309358330 
Slade, M., Amering, M., \& Oades, L. (2008). Recovery: an international perspective. Epidemiologia e Psichiatria Sociale, 17, 128-137. doi: 10.1017/S1121189X00002827

Slade, M., Amering, M., Farkas, M., Hamilton, B., O'Hagan, M., Panther, G., \& Whitley, R. (2014). Uses and abuses of recovery: implementing recovery-oriented practices in mental health systems. World Psychiatry, 13, 12-20. doi: 10.1002/ wps. 20084

Stainton Rogers, R. (1995). Q methodology. In J. A. Smith, R. Harré, \& L. Van Langenhove (eds), Rethinking Methods in Psychology (pp. 178-192). Sage.

Star Wards (2017). Star Wards. URL: www.starwards.org.uk/ (accessed October 2020).

Watts, S., \& Stenner, P. (2012). Doing Q Methodological Research: Theory, Method \& Interpretation. Los Angeles: Sage Publications Ltd.

Whitley, R., \& Drake, R. E. (2010). Recovery: a dimensional approach. Psychiatric Services, 61, 1248-1250. doi: 10.1176/ps. 2010.61.12.1248

Windell, D., \& Norman, R. M. (2013). A qualitative analysis of influences on recovery following a first episode of psychosis. International Journal of Social Psychiatry, 59, 493-500. doi: 10.1177/0020764012443751

Wood, L., Price, J., Morrison, A., \& Haddock, G. (2013). Exploring service users perceptions of recovery from psychosis: a Q-methodological approach. Psychology and Psychotherapy: Theory, Research and Practice, 86, 245-261. doi: 10.1111/j. 2044-8341.2011.02059.x

Wood, L., \& Alsawy, S. (2017). Recovery in psychosis from a service user perspective: a systematic review and thematic synthesis of current qualitative evidence. Community Mental Health Journal, 54, 793-804. doi: 10.1007/s10597-0170185-9

Wood, L., Williams, C., Billings, J. \& Johnson, S. (2019) The therapeutic needs of psychiatric in-patients with psychosis: a qualitative exploration of patient and staff perspectives. British Journal of Psychiatry Open. https://doi.org/10.1192/bjo. 2019.33

Cite this article: Douglas C, Wood L, and Taggart D (2022). Recovery priorities of people with psychosis in acute mental health in-patient settings: a Q-methodology study. Behavioural and Cognitive Psychotherapy 50, 1-14. https://doi.org/ $10.1017 /$ S1352465820000892 